\title{
A Longitudinal Analysis of the Relationship between Positive and Negative Affect and Health
}

\author{
Tamara Ambrona1, Belén López-Pérez² \\ ${ }^{1}$ Universidad de Burgos, Burgos, Spain \\ ${ }^{2}$ School of Psychology, Plymouth University, Plymouth, UK \\ Email: tambrona@ubu.es
}

Received 18 February 2014; revised 16 March 2014; accepted 12 April 2014

Copyright (C) 2014 by authors and Scientific Research Publishing Inc.

This work is licensed under the Creative Commons Attribution International License (CC BY). http://creativecommons.org/licenses/by/4.0/

(c) (i) Open Access

\begin{abstract}
The present article analyses the influence of positive and negative affect on health. The sample consists of 113 first-year undergraduates (76.1\% female, $21.2 \%$ male and $2.7 \%$ unknown), with an age range of 18 to 27 years $(M=19.12, S D=1.77)$. Participants were asked to fill out the Positive and Negative Affect Scale (PANAS), physical health was measure with one scale of the General Health Survey (SF-20), one month and one year later of filling out the PANAS. We used a structural equation modelling to test longitudinal relationships between positive and negative affect and health. As we expected, PA and NA predicted health measured one month later and one year later, respectively. Longitudinal analyses over successive 1-month and 1-year intervals revealed reciprocal effects between health and negative and positive affect. The implications for research on health and emotions are discussed.
\end{abstract}

\section{Keywords}

Positive Affect, Negative Affect, Health

\section{Introduction}

There is a large body of research focused on the relationship between affect, positive traits and physical health. Affect has been divided considering its emotional valence in positive and negative (Watson, Clark, \& Tellegen, 1988). Although there are fluctuations in the levels of positive or negative affect a given person's experiences at different points in time, the stability of self-reports of negative affect (NA) and positive affect (PA) is impressive (Watson, 1988a, 1988b). In this sense, research has revealed that some people report experiencing greater amounts of positive emotions than do others and are typically referred to as high-positive-affect (or high-PA) 
individuals. People who are high in positive affect are, for example, consistently more likely to describe themselves as enthusiastic, confident, and excited than people who are low in positive affect. On the other hand, some individuals' daily lives are characterized by greater amounts of negative affective states than others, and they are often referred to as high-negative-affect (or high-NA) people.

Going back to health, NA is associated with a number of physical and mental health outcomes (Chida \& Hamer, 2008; Kiecolt-Glaser et al., 2002; Kubzansky \& Kawachi, 2000), and has been of interest to scholars for quite some time. More recently, scholars have also started to examine the role of PA, with some initial studies suggesting that PA may also be an important factor for understanding physical health (Pressman \& Cohen, 2005).

Associations between NA, PA and self-reported physical health have been demonstrated in the literature, but the vast majority of these studies have used cross-sectional designs (Lyubomirsky et al., 2005; Suls \& Bunde, 2005). As such, important conceptual questions remain unanswered. First, the causal direction underlying the association between affect and physical health has yet to be resolved. Second, many studies examining the effect of affect on health fail to compare the effects of PA and NA simultaneously, which leaves questions regarding which construct explains most of the variance in physical health. Finally, only perceive health is accounted without considering markers of real and actual health.

The present investigation used a longitudinal design to empirically investigate the directionality of self-reported physical health and affect. In contrast to cross-sectional analyses based on ordinary least-squares regression, estimation of a longitudinal model permitted the assessment of hypothesized reciprocal relations between optimism, affect and physical health complaints across time, as well as a comparison of the relative strength of the lagged effects in each direction (Dwyer, 1983). We measured NA and PA (time 1) and one month later we measured the perceived health (time 2), repeating the assessment one year later (time 3).

\section{Method}

\subsection{Participants and Procedure}

One hundred and thirteen first-year undergraduates (76.1\% female, $21.2 \%$ male and 2.7\% unknown), with an age range of 18 to 27 years $(M=19.12, S D=1.77)$ accepted to participate.

All participants were run individually. On their arrival in the laboratory, each participant was given a brief introduction about the study and a consent form. After reading the introduction and signing the consent form, they were given some instructions and left alone.

They were asked to write a personal code number (their last four numbers of their IDs) in order to identified them anonymously and match their results from different parts of the research. Participants were asked to fill out The Positive and Negative Affect Scale (PANAS; Watson et al., 1988; Spanish adaptation by Sandín et al., 1999). This scale was used to measure PA and NA. Each scale consists of 10 items that represent characteristics of either high PA or high NA. Characteristics assessing NA include scared, ashamed and jittery whereas descriptors assessing positive affect include enthusiastic, excited, and happy. Respondents indicated on a 5-point scale the extent to which they had experienced each mood state during the previous one-week period. Coefficients alpha were .88 and .85 for PA and NA, respectively. One month later, participants were contacted again to complete the second part of the research; they were given another brief introduction. Once they signed the consent form they completed another set of questionnaires in a randomize order. Participants answered two scales of the 20item short-form of the General Health Survey (SF-20; Stewart, Hays, \& Ware, 1988). For the purpose of this research participants only completed the health perception scale, which is a 5-item scale that aims to measure people's perception on their own health. Coefficient alpha was .79.

\subsection{Hypotheses}

We expect that PA and NA will predict health measured on month later and one year later.

\section{Results}

\subsection{Model Selection}

To investigate the relationships between physical health and affect, we sought a longitudinal model that would 
capture two key features of the data. We wished to use a model that permitted tests of the lagged relationships of both the affect $\rightarrow$ health relationship and the health $\rightarrow$ affect relationship so that causal precedence could be assessed. One model that captures both of these features is the cross-lagged panel model (Biesanz, 2012; Kessler \& Greenberg, 1981). In this model, lagged bidirectional relationships can be examined, giving rise to the possibility of establishing causal precedence. The effect of X (e.g., physical health) on Y (e.g., negative affect; positive affect) 1 month and year later can be estimated controlling for the value of $\mathrm{Y}$ observed 1 month and year previously. Similarly, the effect of Y on X 1 month and year later can be estimated controlling for the value of X observed 1 month and year previously.

\subsection{Model Specification and Selection}

To examine the relations between physical health and affect, the models were estimated using AMOS 21. In specifying the measurement component of the model, scores on the subscale of the SF-20 was used as indicator of the physical health construct. Similarly, for PA and NA, two indicators were used for each construct. These were computed by summing across 1) the first ten and 2) the second ten PANAS items measuring each affective domain.

In terms of model specification, structural paths reflecting the cross-lagged effects between physical health measured one month later, physical health measured on year later, NA and PA were specified as free to be estimated.

\subsection{Assessment of Model Fit}

Most researchers advocate using multiple fit indices for evaluating model fit (Hoyle \& Panter, 1995; Hu \& Bentler, 1999). Currently, the most rigorous evaluation of fit criteria has been conducted by $\mathrm{Hu}$ and Bentler (1999). These researchers recommend using a combination of the standardized root mean square residual (SRMR; expected to be .08 or less), the Comparative Fit Index (CFI; Bentler, 1990), which is expected to be .95 or greater, and the Root Mean Square Error of Approximation (RMSEA; Steiger, 1990). Browne and Cudeck(1993) suggest that values of the RMSEA of .05 or less indicate a close fit; values between .05 and .08 indicate adequate fit; values greater than .10 indicate room for improvement in the model. Here we report all three measures (SRMR, CFI, RMSEA). Since these indices do not localize sources of poor fit within a specified model, the normalized residuals and modification indices generated by AMOS 21 were inspected to obtain more detailed diagnostic information.

We tested the fit of the model which specified cross-lagged associations between NA, PA and health. The fit was acceptable, as reflected by CFI $=.97$, RMSEA $=.03$ and SRMR $=.05$. Inspection of the maximum likelihood parameter estimates associated with the model revealed significant lagged reciprocal associations between NA, PA and self-reported physical health (NA, PA health one month later and health one year later NA, PA). The final latent model can be seen in the Figure 1.

\subsection{A Test of Equality of Cross-Lagged Associations between PA, NA and Health}

In a second alternative model, a formal test of the equality of cross-lagged relationships between physical health measured one month later and one year later and PA and NA was examined. To test this hypothesis, the structural parameters were constrained to be equal. For the relationship between PA and health measured one month

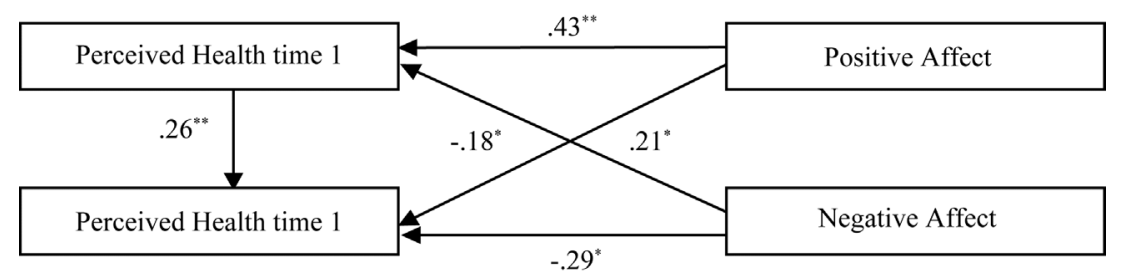

Figure 1. Final latent model of physical health and affect. Correlations among exogenous variables, autocorrelations among errors of measurement in the manifest variables, and synchronous correlations among structural disturbances have been omitted. All coefficients are standardized $\left({ }^{*} p<.05 ;{ }^{* * *} p<.01\right)$. 
later a $\chi^{2}$ difference test indicated that the specification of equal cross lagged effects failed to significantly degrade the fit of the model (i.e. significant increase the model chi-square) relative to the model in which these cross-lagged effects were not constrained to equality $\left(\chi^{2}\right.$ change $=.09$, $d f$ change $=1, p=.76$ ). This result suggested that the effect of PA on subsequent physical health measured one month after was not significantly larger than the effect of physical health on subsequent PA. The same results were obtained for the comparison between PA and health measured one year later $\left(\chi^{2}\right.$ change $=.15, d f$ change $\left.=1, p=.70\right)$, NA and health measured one month later $\left(\chi^{2}\right.$ change $=.18, d f$ change $\left.=1, p=.50\right)$ and NA and health measured one year later $\left(\chi^{2}\right.$ change $=.46$, $d f$ change $=1, p=.67)$.

\section{Discussion}

The results of this research suggest that NA and PA both have an effect on physical health. This is line with previous research that suggests the reciprocal effect of affect and health. The relationship between negative affect and health seem to be supported by the disability hypothesis that adverse consequences engendered by health problems (e.g., chronic pain), result in higher levels of NA (Powell, Johnston, \& Johnston, 2008). The finding of reciprocal effect of PA and health seems to support previous research on the relationship between this kind of affect and health (Lyubomirsky et al., 2005).

\section{Conclusion}

We employed a rigorous longitudinal structural equation modelling analysis to test the proposed relationships among affect and health. It should be noted that the ability to test associations among variables that were corrected for random measurement error avoids potential attenuation bias and the underestimation of relationships.

The data presented here are based on self-reports, which may bring several interpretative problems. First, there is a potential problem of subjective bias. In this sense, it is possible that two individuals who are indistinguishable in terms of objective health status may report large subjective differences in health. A way to avoid this potential bias could be the use of a more objective assessment of health status. A second related problem could be monomethod bias, as the same people reported about all the variables, that health and affect. For purely methodological reasons alone, the correlations between these variables are expected to be larger than when measures are completed by different respondents.

Despite all of these biases, the present research uses a longitudinal methodology that allows testing the relationships between health, PA and NA. In this sense more research is needed to test the role of mediation variables that can account more information for the relationships between health and affect.

\section{References}

Bentler, P. M. (1990). Comparative Fit Indexes in Structural Models. Psychological Bulletin, 107, 238-246. http://dx.doi.org/10.1037/0033-2909.107.2.238

Biesanz, J. C. (2012). Autoregressive Longitudinal Models. In R. H. Hoyle (Ed.), Handbook of Structural Equation Modelling (pp. 459-471). New York: Guilford Press.

Browne, M. W., \& Cudeck, R. (1993). Alternative Ways of Assessing Model Fit. In: K. A. Bollen, \& J. S. Long (Eds.), Testing Structural Equation Models (pp. 136-162). Beverly Hills, CA: Sage.

Chida, Y., \& Hamer, M. (2008). Chronic Psychosocial Factors and Acute Physiological Responses to Laboratory-Induced Stress in Healthy Populations: A Quantitative Review of 30 Years of Investigations. Psychological Bulletin, 134, 829-885. http://dx.doi.org/10.1037/a0013342

Dwyer, J. H. (1983). Statistical Models for the Social and Behavioral Sciences. New York: Oxford University Press.

Hoyle, R. H., \& Panter, A. T. (1995). Writing about Structural Equation Models. In R. H. Hoyle (Ed.), Structural Equation Modeling: Concepts, Issues, and Applications (pp. 158-176). Thousand Oaks, CA: Sage.

Hu, L., \& Bentler, P. M. (1999). Cutoff Criteria for Fit Indixes in Covariance Structure Analysis: Conventional Criteria versus New Alternatives. Structural Equation Modeling, 6, 1-55. http://dx.doi.org/10.1080/10705519909540118

Kessler, R. C., \& Greenberg, D. F. (1981). Linear Panel Analysis. New York: Academic Press.

Kiecolt-Glaser, J. K., McGuire, L., Robles, T. F., \& Glaser, R. (2002). Psychoneuroimmunology: Psychological Influences on Immune Function and Health. Journal of Consulting and Clinical Psychology, 70, 537-547.

http://dx.doi.org/10.1037/0022-006X.70.3.537 
Kubzansky, L. D., \& Kawachi, I. (2000). Going to the Heart of the Matter: Do Negative Emotions Cause Coronary Heart Disease? Journal of Psychosomatic Research, 48, 323-337. http://dx.doi.org/10.1016/S0022-3999(99)00091-4

Lyubomirsky, S., King, L., \& Diener, E. (2005). The Benefits of Frequent Positive Affect: Does Happiness Lead to Success? Psychological Bulletin, 131, 803-855. http://dx.doi.org/10.1037/0033-2909.131.6.803

Powell, R., Johnston, M., \& Johnston, D. W. (2008). The Effects of Negative Affectivity on Self-Reported Activity Limitations in Stroke Patients: Testing the Symptom Perception, Disability and Psychosomatic Hypotheses. Psychology and Health, 23, 195-206. http://dx.doi.org/10.1080/14768320701204153

Pressman, S. D., \& Cohen, S. (2005). Does Positive Affect Influence Health? Psychological Bulletin, 131, 925-971. http://dx.doi.org/10.1037/0033-2909.131.6.925

Sandín, B., Chorot, R., Lostao, L., Joiner, T. E., Santed, M. A., \& Valiente, R. M. (1999). Escalas PANAS de afecto positivo y negativo: Validación factorial y convergencia transcultural. Psicothema, 2, 37-51.

Steiger, J. H. (1990). Structural Model Evaluation and Modification. Multivariate Behavioral Research, 25, $214-212$. http://dx.doi.org/10.1207/s15327906mbr2502_4

Stewart, A., Hays, R. D., \& Ware, J. E. (1988). The MOS Short-Form General Health Survey: Reliability and Validity in a Patient Population. Medical Care, 26, 724-735. http://dx.doi.org/10.1097/00005650-198807000-00007

Suls, J., \& Bunde, J. (2005). Anger, Anxiety, and Depression as Risk Factors for Cardiovascular Disease: The Problems and Implications of Overlapping Affective Disorders. Psychological Bulletin, 131, 260-300. http://dx.doi.org/10.1037/0033-2909.131.2.260

Watson, D. (1988a). Intraindividual and Interindividual Analyses of Positive and Negative Affect: Their Relations to Health Complaints, Perceived Stress, and Daily Activities. Journal of Personality and Social Psychology, 54, 1020-1030. http://dx.doi.org/10.1037/0022-3514.54.6.1020

Watson, D. (1988b). The Vicissitudes of Mood Measurement: Effects of Varying Descriptors, Time Frames, and Response Formats on Measures of Positive and Negative Affect. Journal of Personality and Social Psychology, 55, 128-141. http://dx.doi.org/10.1037/0022-3514.55.1.128

Watson, D., Clark, L. A., \& Tellegen, A. (1988). Development and Validation of Brief Measures of Positive and Negative Affect The PANAS Scales. Journal of Personality and Social Psychology, 54, 1063-1070.

http://dx.doi.org/10.1037/0022-3514.54.6.1063 